\title{
Computational Fluid Dynamics of Two-Opposed-Jet Microextractor
}

\author{
Pritam V. Hule, B. N. Murthy, and Channamallikarjun S. Mathpati \\ Department of Chemical Engineering, Institute of Chemical Technology, Matunga, Mumbai 400 019, India \\ Correspondence should be addressed to Channamallikarjun S. Mathpati, cs.mathpati@ictmumbai.edu.in
}

Received 28 October 2011; Accepted 21 February 2012

Academic Editor: Sreepriya Vedantam

Copyright () 2012 Pritam V. Hule et al. This is an open access article distributed under the Creative Commons Attribution License, which permits unrestricted use, distribution, and reproduction in any medium, provided the original work is properly cited.

Liquid-liquid extraction is an important unit operation in chemical engineering. The conventional designs such as mixer settler have lower-energy efficiency as the input energy is dissipated everywhere. Experimental studies have proved that the novel designs such as two-opposed-jet contacting device (TOJCD) microextractor allow energy to be dissipated close to the interface, and major part of energy is used for drop breakup and enhancement of surface renewal rates. It is very difficult to estimate the local variation of energy dissipation $(\varepsilon)$ using experiments. Computational fluid dynamics (CFD) has been used to obtain $\varepsilon$ at different rotating speed of the top disc and nozzle velocity. In this work, performance analysis of TOJCD microextractor has been carried out using Reynolds stress model. The overall $\varepsilon$ value was found in the range of 50 to $400 \mathrm{~W} / \mathrm{kg}$ and shear rate in the range of $1000001 / \mathrm{s}$. A semiempirical correlation for $k_{L} \underline{a}$ is proposed, and parity plot with experimental data has been plotted.

\section{Introduction}

Liquid-liquid extraction (LLE) is an important unit operation in chemical engineering. Typical applications of the LLE are in metal extraction, aromatics nitration and sulfonation, polymer processing, waste water treatment as well as food and petroleum industries. LLE is a mass transfer operation in which a liquid solution (the feed) is contacted with an immiscible or nearly immiscible liquid (solvent) that exhibits preferential affinity or selectivity towards one or more of the components in the feed. Two streams result from this contact: the extract, which is the solvent-rich solution containing the desired extracted solute, and the raffinate, the residual feed solution containing little solute. The conventional designs such as mixer settler often have lower energy efficiency as the input energy is dissipated everywhere in the extractor.

The transfer of solute from one phase to another is controlled by diffusion across the interface and often rate limiting. The process can be intensified and energy efficiency can be improved by novel designs such as two-opposedjet contact device [1,2], annular centrifugal extractors [3], impinging jet contactors [4], pulsed sieve plate extraction columns [5], and so forth. Experimental studies have proved that these novel designs offer higher energy efficiency. High energy dissipation and shear rates are used for breakup and enhancement of surface renewal rates. However, it is very difficult to estimate the local variation of energy dissipation using experiments. Computational fluid dynamics (CFD) can be used in such cases to estimate the local variation of energy dissipation and optimize the hardware configuration and selection of operating conditions [6].

The present work deals with Reynolds stress modelling of two-opposed-jet contact device designed by Dehkordi $[1,2]$. This equipment can also be classified as microextractor and hence termed as "two-opposed-jet microextractor" in the present study. The principle of opposed jets is to bring the two jets flowing along the same axis in the opposite direction into collision. As the result of such a collision, a relatively narrow zone, called the impingement zone of high turbulence intensity, is created which offers excellent conditions for intensifying heat- and mass-transfer rates. The extensive details of impinging jet technique and applications for various processes can be found in Tamir [7] and Saien et al. [4].

Impinging jet system offers lot of complexities in modelling due to stagnation point, significant variations, and redistribution of Reynolds stress and highly anisotropic flow. 
The standard $k-\varepsilon$ model will not work in simulating these types of flow accurately due to inherent assumption of isotropy. As the stagnation point is approached, there is a significant redistribution of energy between various stress components and hence Reynolds stress modelling (RSM) with appropriate pressure strain model is required. It is well known that for single-phase cases CFD tool is proven to be reliable; for instance, flow pattern in stirred tank [8], jet reactor [9], and centrifugal extractor [10] was well predicted. In view of this, in the present work a very fine and structured mesh with good quality has been employed to ensure better predictions.

The main objectives of present work were to obtain energy dissipation rate and shear rate distributions in two-opposed-jet microextractor for various geometric and operating conditions. Further, the energy dissipation from CFD data has been used to develop a semiempirical model for overall mass transfer coefficient which takes into account fundamental basis of turbulence phenomena. The energy supplied in the extractor is utilized for (i) creating liquid motion, (ii) creation of new surface, that is, drop breakup and increasing interfacial area, and (iii) turbulent fluctuations at liquid-liquid interface which improve true mass transfer coefficient $\left(k_{L}\right)$. Point (ii) contributes to major utilization of energy input in case of microextractor. To quantify this, two-phase simulations with interphase forces need to be carried out; however, CFD tool is still not reliable for realistic predictions of immiscible mixing behaviour. Therefore, in the present work, an attempt has been made to understand this system using single phase simulations. The experimental mass transfer coefficient is correlated with total energy dissipated in the microextractor. The focus is not on getting individual components of energy utilization (i), (ii), and (iii), but to get overall dissipation rate. This can be obtained using single-phase simulations. In the present work, singlephase CFD simulation using Reynolds stress model has been carried out for preliminary analysis of microextractor.

\section{Previous Work}

In this section, numerical and experimental efforts to understand hydrodynamics and turbulent statistics of impinging jet have been discussed. Wang and Mujumdar [11-13] studied mixing characteristics of multiple and multiset turbulent opposing jets using standard $k-\varepsilon$ model. The effects of turbulence models, model constants, operating conditions, geometric parameters, flow conditions at the nozzle exit, turbulent Schmidt number as well as unequal opposing jets on mixing in the three-dimensional confined turbulent opposing jet flow were examined systematically. They observed that multiple opposing jets achieve better mixing than single opposing jets in the mixer studied. Compared to the single opposing jets, the multiple opposing jets yield mixing which is poorer in the dome, the impingement zone, and its vicinity, but better in the downstream zones after a critical value of axial distance. The total pressure drop for $n=2$ is roughly 3.5 times higher than that for $n=4$ due largely to the higher inlet velocity in the former at a given total mass flow rate. This demonstrates a significant power reduction without detriment to mixing performance for multiple opposing jets $(n \geq 3)$ compared to single opposing jets $(n=2)$ and thus the economic benefits of such mixers.

Abdel-Fattah [14] studied two-dimensional impinging circular twin-jet flow numerically (standard $k-\varepsilon$ model) and experimentally. The parameters studied were jet Reynolds number, nozzle to plate spacing, nozzle to nozzle centerline spacing, and jet angle. It was concluded that the stagnation primary point moves away in the radial main flow direction by increasing the jet angle. This shift becomes stronger by increasing the nozzle to nozzle centerline spacing. A secondary stagnation point was set up between two jets. The value of pressure at this point decreases by decreasing Reynolds number and/or increasing the jet angle. Turbulent kinetic energy increases within each vortex region; this increment decreases by increasing of jet angle and/or the nozzle to plate spacing.

Gavi et al. [15] carried out CFD study and scaleup of confined impinging jet reactors for precipitation of nanoparticles. Mixing at the molecular level is modelled with a presumed probability density function approach: the direct quadrature method of moments coupled with the interaction by exchange with the mean (DQMOMIEM) model. Comparison between experimental data and simulations in a wide range of operating conditions showed excellent agreement. Best agreement with experimental data was found when the RSM and the Standard $k-\varepsilon$ model coupled with enhanced wall treatment were used.

Kleingeld et al. [16] carried out numerical modelling of impinging jet reactor. The model for the prediction of the interfacial area production in IJ reactor was developed and implemented in the form of a Monte Carlo simulation, based on the fact that bubble breakup in a turbulent environment is governed by the interactions of bubbles with turbulent eddies. Due to this intimate contact between phases, mass transfer coefficients $\left(k_{L}\right)$ of up to $1.5 \times 10^{-3} \mathrm{~m} / \mathrm{s}$ have been realised, which, coupled with values of the specific interfacial area (a) of $8-18000 \mathrm{~m}^{2} / \mathrm{m}^{3}$, have yielded volumetric mass transfer coefficients $\left(k_{L} a\right)$ of up to $22 \mathrm{~s}^{-1}$ which are orders of magnitude higher than typical values obtained by conventional systems.

Marchisio [17] carried out LES of mixing and reaction in confined IJ reactor. Subgrid-scale mixing is described with a presumed PDF approach, namely, DQMOM-IEM. Model predictions compare well with experimental data (and Reynolds averaged Navier Stokes equation predictions from our previous work); comparison was carried out for two sets of initial concentration and two different reactor geometry. The analysis shows that CIJRs are indeed interesting devices, because of the high mixing efficiency and because of the absence of stagnant and recirculation zones. Niamnuy and Devahastin [18] have studied the effects of geometry and operating conditions on the mixing behavior of IJ mixer. For a fixed value of $d / D$, an increase in the value of the jet Reynolds number led to a better mixing in the impingement zone and its vicinity. This mixing behavior persisted until a critical value of dimensionless axial distance $(x / D)$ was reached beyond which the mixing quality changed. For a mixer with two sets of inlet jets, it was found that a larger 
spacing between the two sets of inlet jets (higher $S / D$ ) resulted in a better mixing in the region between the sets of inlet jets but yielded no significant difference in the required main flow channel length to obtain a well-mixed condition.

Li et al. [19] studied the stagnation point offsets of turbulent opposed jets at various exit velocity ratios, and nozzle separations were experimentally studied by a hotwire anemometer, smoke-wire technique, and numerically simulated by Reynolds stress model (RSM). Results show that, for $2 D \leq L \leq 4 D$ (where $L$ is nozzle separation and $D$ is nozzle diameter), the position of the impingement plane is unstable and oscillates within a region between two relative stable positions when the exit velocities are equal. The instability and sensitivity of the stagnation point offset to the small difference of the exit velocities of opposed jets may ascribe to the instability of the large-scale vortices in the boundary layers of opposed jets. The study of the stagnation point offset of impinging streams is crucial for the effective use of such flow in industrial applications because imbalance of the exit flux of impinging streams is inevitable practically. The most important find of our study is that there exists a region of $2 D \leq L \leq 8 D$, in which the stagnation point of opposed jets is very sensitive to the exit velocity ratio, and small difference (3\% or less) of exit velocity can cause the stagnation point to deviate obviously.

Unger and Muzzio [20] have measured concentration profiles and mixing performance in IJ reactors using laserinduced fluorescence (LIF) technique. Flow structures were visualized by imaging concentration distributions at five vertical planes throughout the mixers. Mixing is quantified for each Reynolds number examined by calculating the overall intensity of segregation. Mixing performance varies substantially as a function of Reynolds number. The results demonstrated the ability of laser-induced fluorescence to quantitatively capture small- and large-scale flow structures and accurately and reproducibly quantify mixing performance in real time for industrially relevant mixing devices. For unsteady-laminar flows $80<\operatorname{Re}_{j}<300$, the jet oscillations which occur in the standard geometry result in better mixing than the swirling motion of the asymmetric jets; flow for the asymmetric jets is mostly steady and similar to flow for $\operatorname{Re}_{j}<80$. For more highly unsteady flows $\operatorname{Re}_{j}>$ 300 , efficient mixing occurs in both geometries although the asymmetric eliminates the dead region in the bottom of the mixer and results in slightly greater overall homogeneity.

Sun et al. [21] studied velocity distribution of two opposed jets using hot film anemometry and CFD. The radial velocities of opposed jets with various exit velocities, nozzle diameters, and nozzle separations were measured experimentally. The normalized radial velocities are selfsimilar across various radial sections at $r \geq 1.5 \mathrm{D}$, and the radial velocity profiles can be described by a Gaussian distribution function. The half-width increases linearly with increasing radial distance at $r \geq 1.5 \mathrm{D}$, and spreading rates of radial jet are about 0.121 . The normalized radial velocity at impingement plane increases firstly and then decreases with the increasing normalized radial distance. The normalized radial velocity is independent on nozzle diameter, nozzle separation, and exit velocity. The maximum radial velocity

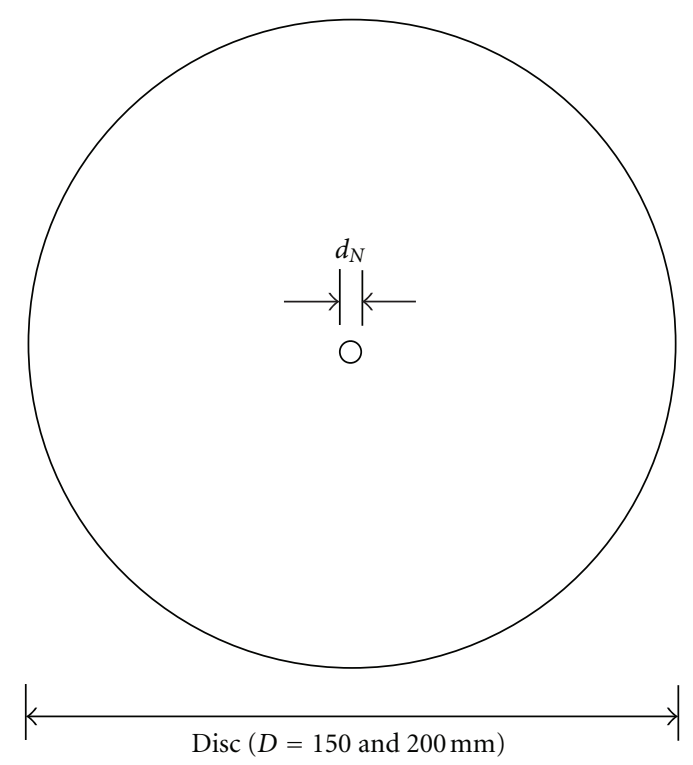

(a)

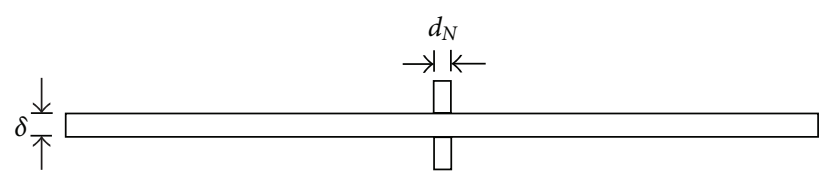

(b)

FIgure 1: Geometric details. (a) Top view and (b) side view.

at impingement plane is proportional to the exit velocity, and it is inversely proportional to the 0.551 th power of the normalized nozzle separation. The position of the maximum radial velocity increases with the nozzle separation at $L / D<1$ and keeps invariant at $L / D \geq 1$.

It can be pointed out from the above-mentioned literature survey that impinging jet technique has been studied widely, and knowledge about the transport phenomena under turbulent conditions has been improved to satisfactory level using experimental and computational fluid dynamics. This understanding can be effectively utilized for design of various equipments as well as performance optimization. In this work, two-opposed-jet microextractor has been studied using Reynolds stress model. The Reynolds stress model is very effective in solving stagnation flows with very strong anisotropy.

\section{Systems under Consideration}

The microextractor geometry is shown in Figures 1(a) and 1(b). It consists of the following parts: (1) two circular disks with dimension of $D(\mathrm{~m}) \times \delta(\mathrm{m})=0.15 \times 0.0015$ and $0.2 \times 0.00015$, where $D$ and $\delta$ are disk diameter and the distance between disks, respectively. The upper disk was rotated at various speeds $(600,1000$, and $1400 \mathrm{rpm})$, and the lower disk was fixed. The aqueous and organic phases were fed into the lower and upper disks, respectively, through nozzle of $0.001 \mathrm{~m}$ diameter. Thus, the contact between the 


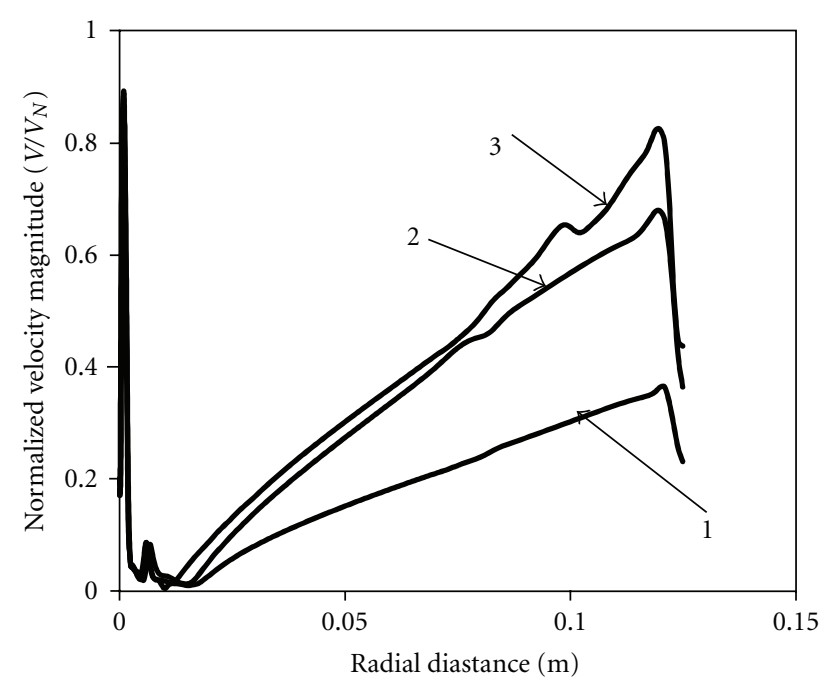

FIGURE 2: Variation of normalized velocity magnitude $\left(V / V_{N}\right)$ along radial coordinate $[z=0.00075 \mathrm{~m}]$ disc diameter: $0.15 \mathrm{~m}$, flow rate: $300 \mathrm{~mL} / \mathrm{min}$, line 1: $600 \mathrm{rpm}$, line 2: $1000 \mathrm{rpm}$, and line 3: $1400 \mathrm{rpm}$.

TABLE 1: Simulation details and results of two-opposed-jet microextractor using RSM.

\begin{tabular}{lcccc}
\hline Sr. no. RPM & $\begin{array}{c}\text { Aq flow rate } Q_{A} \\
\text { (mL per min.) }\end{array}$ & $\begin{array}{c}\text { Disc diameter } \\
(\mathrm{m})\end{array}$ & $\begin{array}{c}\text { Nozzle velocity } \\
\mathrm{m} / \mathrm{s}\end{array}$ \\
\hline 1 & 600 & 300 & 0.15 & 6.36 \\
2 & 1000 & 300 & 0.15 & 6.36 \\
3 & 1400 & 300 & 0.15 & 6.36 \\
4 & 600 & 190 & 0.15 & 4.03 \\
5 & 1000 & 190 & 0.15 & 4.03 \\
6 & 1400 & 190 & 0.15 & 4.03 \\
7 & 600 & 110 & 0.15 & 2.33 \\
8 & 1000 & 110 & 0.15 & 2.33 \\
9 & 1400 & 110 & 0.15 & 2.33 \\
10 & 600 & 300 & 0.20 & 6.36 \\
11 & 1000 & 300 & 0.20 & 6.36 \\
12 & 1400 & 300 & 0.20 & 6.36 \\
13 & 600 & 190 & 0.20 & 4.03 \\
14 & 1000 & 190 & 0.20 & 4.03 \\
15 & 1400 & 190 & 0.20 & 4.03 \\
16 & 600 & 110 & 0.20 & 2.33 \\
17 & 1000 & 110 & 0.20 & 2.33 \\
18 & 1400 & 110 & 0.20 & 2.33 \\
\hline
\end{tabular}

two phases took place within the extraction compartment only. The present study is restricted to single phase using water as working fluid. The reason for using single phase simulations has already been explained in introduction. The ratio of flow rates through the top and bottom nozzles was kept unity for all the simulations. Flow rates considered in the present work were (i) $5 \times 10^{-5} \mathrm{~m}^{3} / \mathrm{s}(300 \mathrm{~mL} / \mathrm{min}$ ), (ii) $3.2 \times 10^{-5} \mathrm{~m}^{3} / \mathrm{s}(190 \mathrm{~mL} / \mathrm{min})$, and (iii) $1.8 \times 10^{-5} \mathrm{~m}^{3} / \mathrm{s}$ $(110 \mathrm{~mL} / \mathrm{min})$. The geometric and operating parameters are taken from the experimental work of Dehkordi [1]. Dehkordi [1] has considered a system where iso-butyric acid in aqueous solution was getting transferred to organic phase (cumene). The objective of present work was to study the hydrodynamics in such microextractors which predict the mass transfer rates. The mass transfer rate is strongly dependent on the energy dissipation profile. The performance of extractor in dependent on (i) jet velocity, (ii) disc rotation speed, (iii) density, and (iv) viscosity of the phase. In the work, effects of disc rotation speed and jet velocity are analyzed.

\section{Governing Equations and Boundary Conditions}

The standard $k-\varepsilon$ model inherently fails to predict properly the anisotropic flow situations (Reynolds [22], Launder [23], and Hanjalić [24]). Reynolds stress model, in theory, can circumvent most of the deficiencies of standard $k-\varepsilon$ model and also it has an ability to predict more accurately each individual stress. A Reynolds stress model solves continuity equation (1), momentum equation (2) six equations for the Reynolds stress (3), and another equation for the dissipation rate $(4)$. The pressure strain term $\left(\Pi_{i j}\right)$ in $(3)$ is the most uncertain term in the RSM. This term is responsible for making turbulence isotropic and redistribution of energy between components $\left\langle u_{1}^{\prime 2}\right\rangle,\left\langle u_{2}^{\prime 2}\right\rangle$, and $\left\langle u_{3}^{\prime 2}\right\rangle$. This improves the accuracy of prediction of turbulence production rate as well as local turbulent kinetic energy dissipation rate $(\varepsilon)$. One has the following:

$$
\begin{aligned}
& \frac{\partial \rho}{\partial t}+\frac{\partial\left\langle u_{i}\right\rangle}{\partial x_{i}}=0 \\
& \rho \frac{\partial\left\langle u_{i}\right\rangle}{\partial t}+\rho\left\langle u_{j}\right\rangle \frac{\partial\left\langle u_{i}\right\rangle}{\partial x_{j}}=-\frac{\partial\langle p\rangle}{\partial x_{i}}+\frac{\partial}{\partial x_{j}}\left(\mu \frac{\partial\left\langle u_{i}\right\rangle}{\partial x_{j}}-\rho\left\langle u_{i}^{\prime} u_{j}^{\prime}\right\rangle\right)
\end{aligned}
$$

$$
\begin{aligned}
& \left\{\rho \frac{\partial \tau_{i j}}{\partial t}\right\}+\left\{\rho\left\langle u_{k}\right\rangle \frac{\partial \tau_{i j}}{\partial x_{k}}\right\} \\
& =\left\{-\rho\left(\tau_{i k} \frac{\partial\left\langle u_{j}\right\rangle}{\partial x_{k}}+\tau_{j k} \frac{\partial\left\langle u_{i}\right\rangle}{\partial x_{k}}\right)\right\}+\left\{\frac{\partial}{\partial x_{k}}\left(\frac{\mu_{t}}{\sigma_{k}} \frac{\partial \tau_{i j}}{\partial x_{k}}\right)\right\} \\
& +\left\{\frac{\partial}{\partial x_{k}}\left(\mu \frac{\partial \tau_{i j}}{\partial x_{k}}\right)\right\}+\left\{-\frac{2}{3} \varepsilon \delta_{i j}\right\}+\left\{\Pi_{i j}\right\},
\end{aligned}
$$

$$
\begin{aligned}
\left\{\rho \frac{\partial \varepsilon}{\partial t}\right\} & +\left\{\rho\left\langle u_{j}\right\rangle \frac{\partial \varepsilon}{\partial x_{j}}\right\} \\
= & \left\{\rho C_{\varepsilon 1} \frac{\varepsilon}{k} \tau_{i j} \frac{\partial\left\langle u_{i}\right\rangle}{\partial x_{j}}\right\}+\left\{\frac{\partial}{\partial x_{j}}\left(\frac{\mu_{t}}{\sigma_{\varepsilon}} \frac{\partial \varepsilon}{\partial x_{j}}\right)\right\} \\
& +\left\{\frac{\partial}{\partial x_{j}}\left(\mu \frac{\partial \varepsilon}{\partial x_{j}}\right)\right\}+\left\{-C_{\varepsilon 2} \rho \frac{\varepsilon^{2}}{k}\right\} .
\end{aligned}
$$

4.1. Boundary Conditions. The top disc has been given rotational boundary condition whereas bottom disc is stationary. 


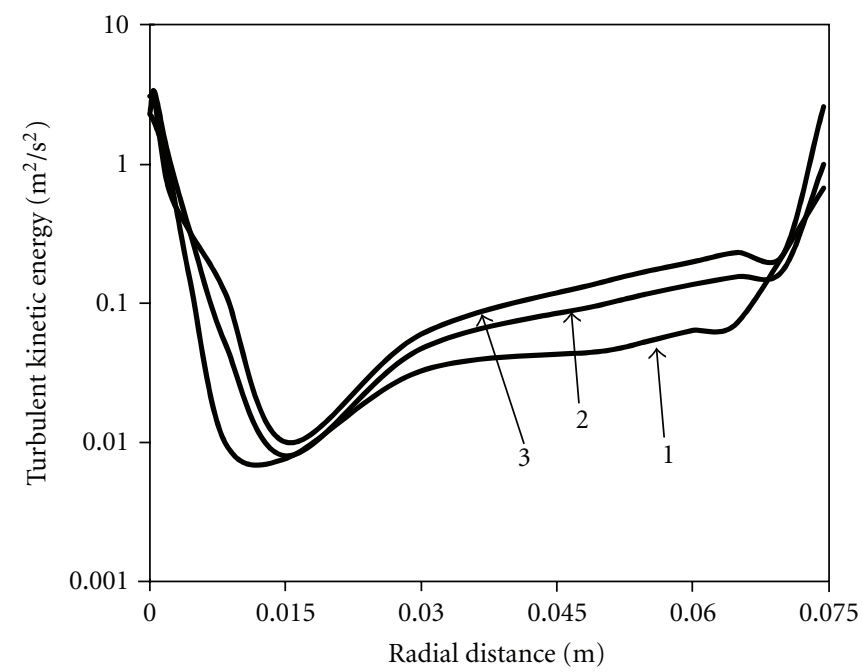

(a)

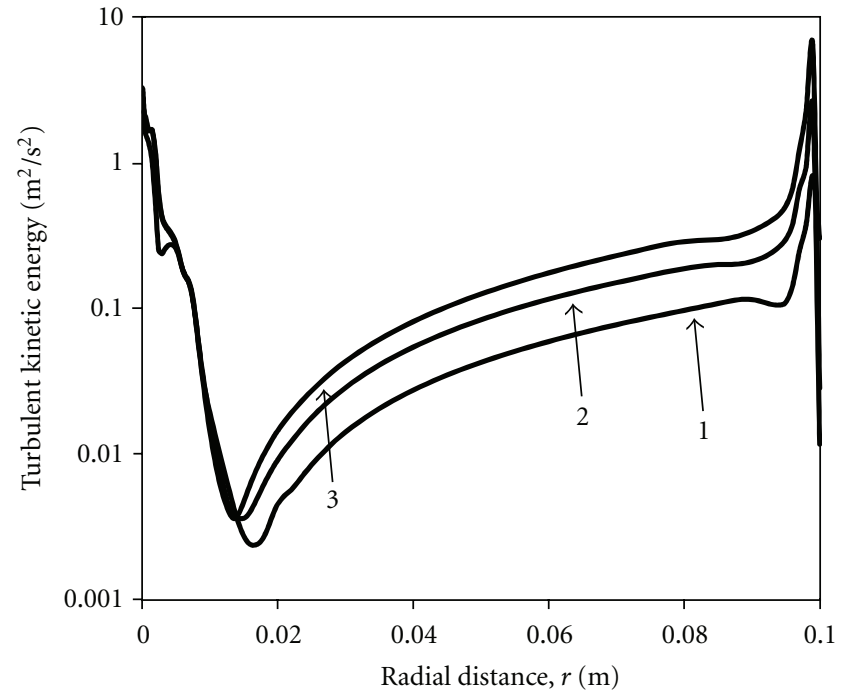

(b)

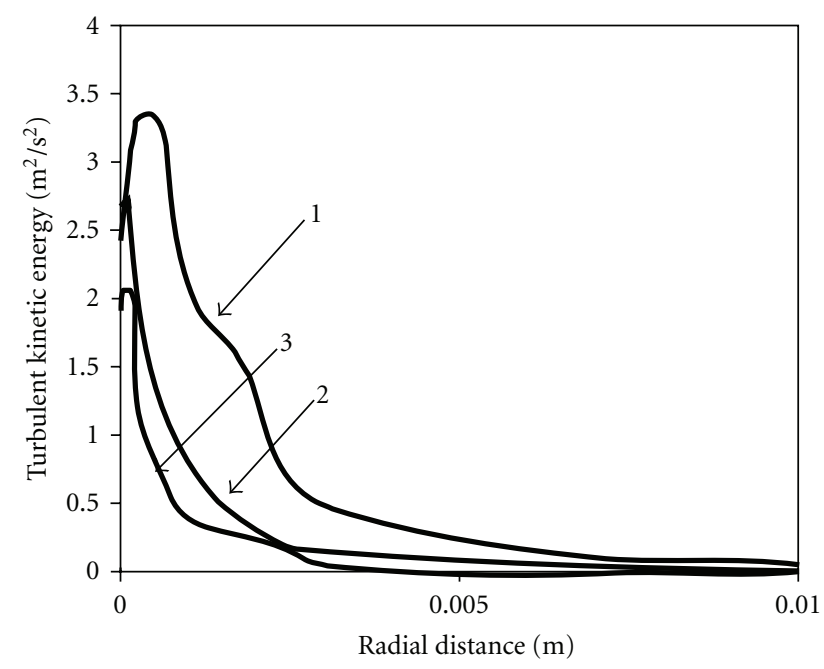

(c)

Figure 3: Variation of turbulent kinetic energy $(k)$ along radial coordinate $[z=0.00075 \mathrm{~m}]$. (a) Disc diameter: $0.15 \mathrm{~m}$, flow rate: $300 \mathrm{~mL} / \mathrm{min}$, line 1: $600 \mathrm{rpm}$, line 2: $1000 \mathrm{rpm}$, line 3: $1400 \mathrm{rpm}$. (b) Disc diameter: $0.20 \mathrm{~m}$, flow rate: $300 \mathrm{~mL} / \mathrm{min}$, line 1: $600 \mathrm{rpm}$, line 2: $1000 \mathrm{rpm}$, line 3: $1400 \mathrm{rpm}$. (c) Disc diameter: $0.15 \mathrm{~m}$, rotation speed: $1000 \mathrm{rpm}$, line 1: $300 \mathrm{~mL} / \mathrm{min}$, line 2: $190 \mathrm{~mL} / \mathrm{min}$, line 3: $110 \mathrm{~mL} / \mathrm{min}$.

No slip condition is imposed on both the discs. Velocity inlet boundary condition is used at top and bottom nozzles. The opening at the end of the discs is given pressure outlet condition.

\section{Simulation Details}

Table 1 summarizes all the cases considered in this study. Hexahedral elements were used for meshing the geometry, and a good quality of mesh was ensured throughout the computational domain using GAMBIT mesh generation tool. In this work, all the computational work has been carried out with finite volume approach using the commercially available software FLUENT 6.2. Further, the secondorder upwind scheme was used for continuity, momentum, and turbulence equations. All the discretised equations were solved in a segregated manner with the Semi-Implicit Method for Pressure Linked Equations (SIMPLEs) algorithm. In the present work, all the solutions were considered to be fully converged when repeated iterations do not decrease the sum of residuals below $1 \times 10^{-4}$. Default model constants have been used for all the RSM parameters. For each case, grid independency study has been carried out using $0.8,1.2$, and 1.5 million cells for disc diameter of $0.15 \mathrm{~m}$ and 1.2, 1.4, and 1.6 million cells for another disc diameter of $0.20 \mathrm{~m}$. The predicted mean shear and turbulent kinetic energy dissipation rate profiles were found to be same for all the three cases. Therefore, the present study employed 1.2 to 1.4 million cells. Further, the clearance between the discs; that is, $0.0015 \mathrm{~m}$ was resolved using 30 elements. 


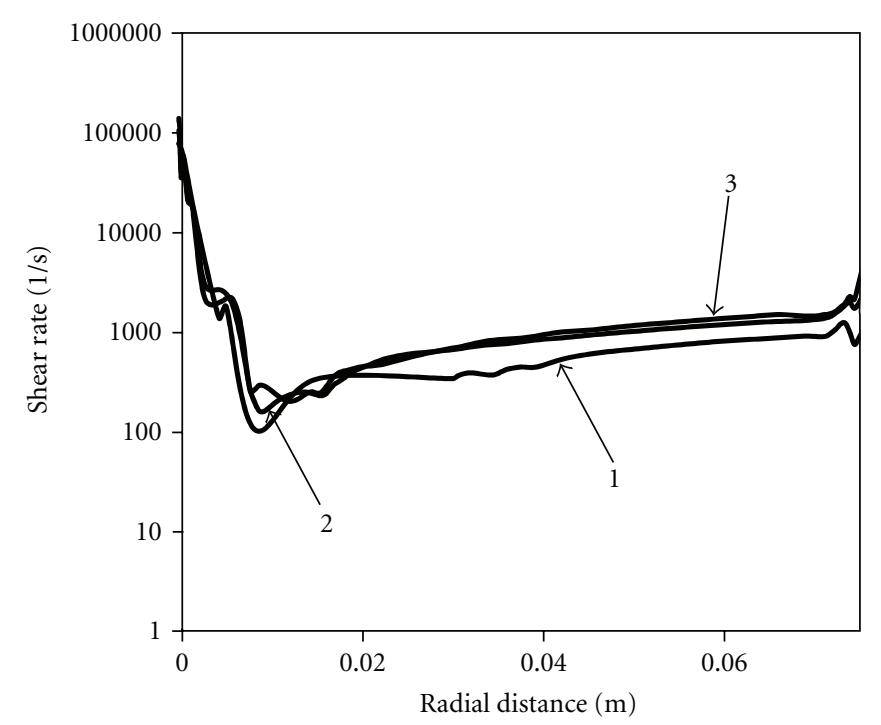

(a)

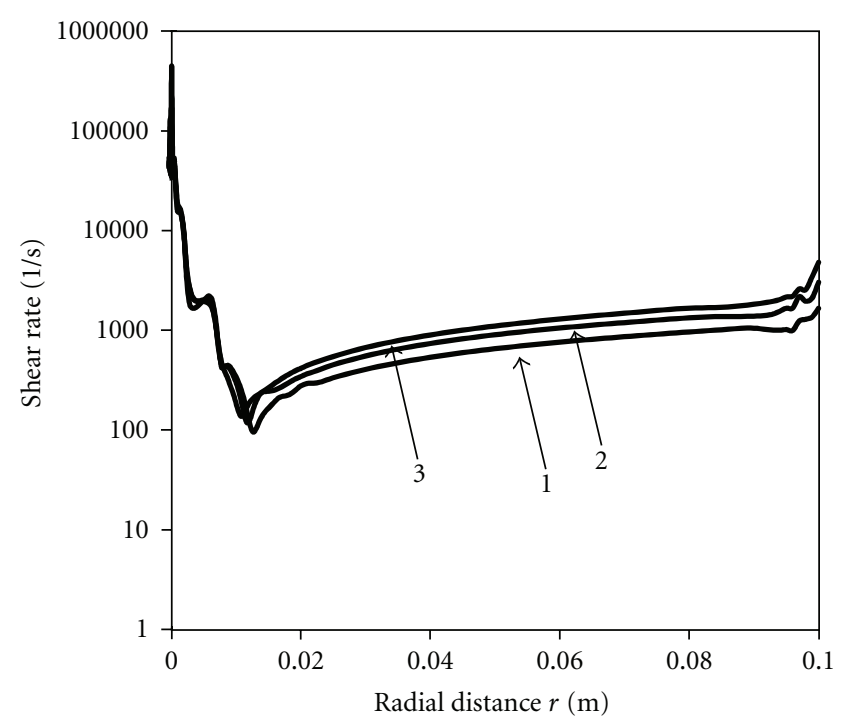

(b)

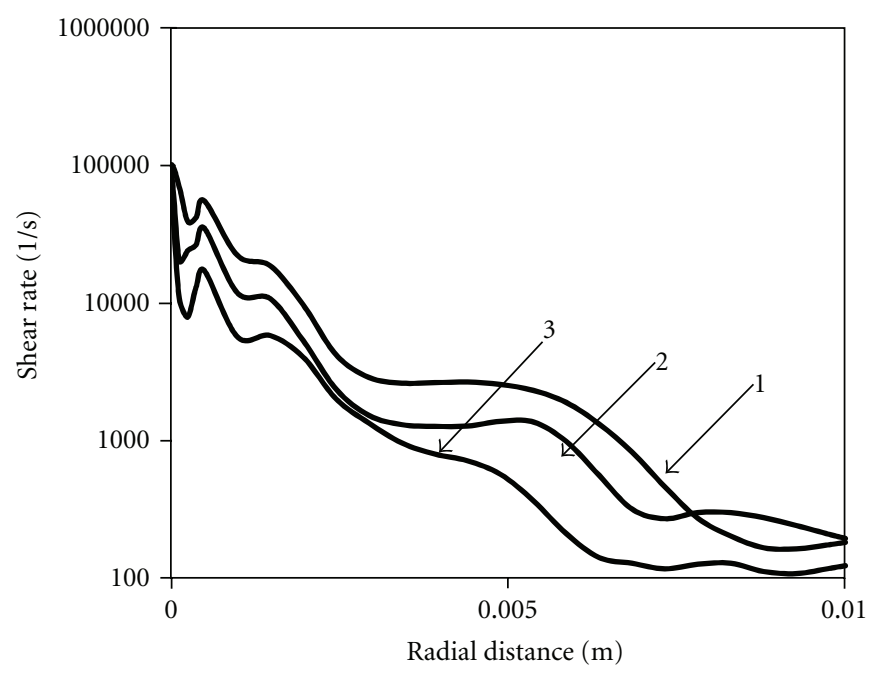

(c)

FIGURE 4: Variation of shear rate along radial coordinate $[z=0.00075 \mathrm{~m}]$. (a) Disc diameter: $0.15 \mathrm{~m}$, flow rate: $300 \mathrm{~mL} / \mathrm{min}$, line 1: $600 \mathrm{rpm}$, line 2: $1000 \mathrm{rpm}$, line 3: $1400 \mathrm{rpm}$. (b) Disc diameter: $0.20 \mathrm{~m}$, flow rate: $300 \mathrm{~mL} / \mathrm{min}$, line 1: $600 \mathrm{rpm}$, line 2: $1000 \mathrm{rpm}$, line 3: $1400 \mathrm{rpm}$. (c) Disc diameter: $0.15 \mathrm{~m}$, rotation speed: $1000 \mathrm{rpm}$, line $1: 300 \mathrm{~mL} / \mathrm{min}$, line 2: $190 \mathrm{~mL} / \mathrm{min}$, line 3: $110 \mathrm{~mL} / \mathrm{min}$.

The simulations were performed on desktop machines with i3 processor and 4 GB RAM. Each simulation took 20 hours on single processor.

\section{Results and Discussion}

In the present study, as stated earlier water flow rates were same through both the top and bottom nozzles which are of the same diameter. Therefore, the jets collide each other at exact mid plane. Hence, all the results are provided at the midplane $(z=0.00075 \mathrm{~m})$. CFD results are presented in the form of velocity, shear rate, turbulence kinetic energy, and its dissipation rate with respect to various geometric (disc diameters) and operating parameters (flow rate $=110 \mathrm{~mL} / \mathrm{min}$ to $300 \mathrm{~mL} / \mathrm{min}$ and rotational speed $=600$ to $1400 \mathrm{rpm}$ ).
Figure 2 shows zero velocity at the point of collision. The velocity shows a maxima close to the point of collision and suddenly drops down, then it gradually increased till $r=$ $D / 2$. This strong variation of velocity generates high shearing action which is in turn responsible for rate of surface renewal as well as drop breakup. It can be seen that flow rate significantly affects the velocity and shear in the central region, and rotation of top disc plays important role away from the centre. For $D=0.15 \mathrm{~m}$ and flow rate of $300 \mathrm{~mL} / \mathrm{min}$, Figure 3(a) shows the turbulent kinetic energy profiles at various disc rotational speeds $(600,1000$, and $1400 \mathrm{rpm})$. The turbulent kinetic energy shows maxima at the centre (collision point) and periphery of the disc (due to highest centrifugal force). At the periphery it is a strong function of rotation speed and disc diameter (Figures 3(a) and 3(b)). 


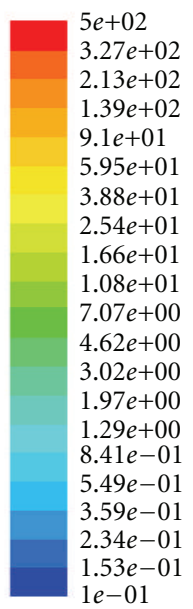

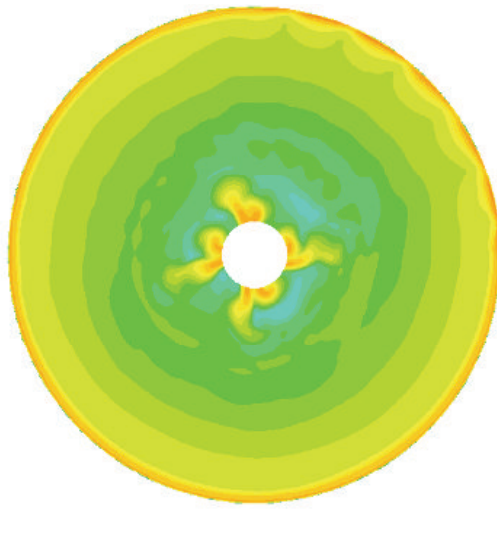

(a)

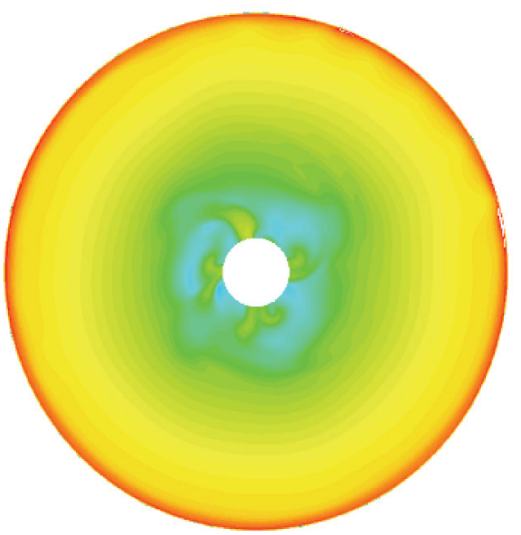

(b)
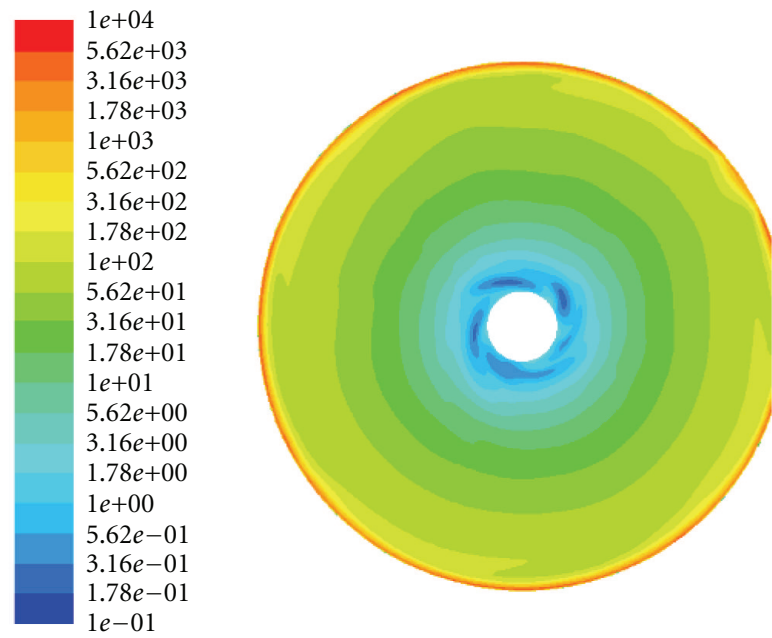

(c)

FIGURE 5: Contour plot of turbulent dissipation rate $(\varepsilon)$ outer region $(r=0.01 \mathrm{~m}$ to $r=0.075 \mathrm{~m})[D=0.2 \mathrm{~m}][z=0.00075 \mathrm{~m}]$. Flow rate: $300 \mathrm{~mL} / \mathrm{min}$, (a) $600 \mathrm{rpm}$, (b) $1000 \mathrm{rpm}$, and (c) $1400 \mathrm{rpm}$.

Figure 3(c) shows the variation of turbulent kinetic energy as a function of flow rate, and it can be observed that the maximum kinetic energy value decreases with decrease in flow rate. Combination of both the high shear and turbulent fluctuations in the central region is responsible for highest turbulence production (turbulence stress $\times$ shear rate) which in turn provides very high dissipation rate. Figures $4(a)-4(c)$ shows variation of shear rate with flow rate and rotational speed. Change in flow rate from $110 \mathrm{~mL} / \mathrm{min}$ $\left(\sim 10,000 \mathrm{~s}^{-1}\right)$ to $300 \mathrm{~mL} / \mathrm{min}\left(\sim 100,000 \mathrm{~s}^{-1}\right)$ has marked effect on shear rate. Figures 5 and 6 show the contour plot of turbulent dissipation rate. Figures $5(a)-5(c)$ show the effect of rotational speed at constant flow rate of $300 \mathrm{~mL} / \mathrm{min}$ for $D=0.2 \mathrm{~m}$. A very high dissipation is obtained at the periphery of the disc. At the flow rate of $300 \mathrm{~mL} / \mathrm{min}$, the average turbulent kinetic energy dissipation rate (TKED) of $10000 \mathrm{~W} / \mathrm{kg}$ is obtained for $1400 \mathrm{rpm}$ and about $500 \mathrm{~W} / \mathrm{kg}$ for $600 \mathrm{rpm}$. In case of $110 \mathrm{~mL} / \mathrm{min}$, the average TKED rates for 600,1000 , and $1400 \mathrm{rpm}$ are 58,150 , and $377 \mathrm{~W} / \mathrm{kg}$, respectively. Figures 6(a)-6(c) show contour plots of the TKE, and it is observed that, with increasing flow rate, the region experiencing high dissipation rate is found to increase.

Figures $7(a)$ and $7(b)$ show the effect of rotational speed for $D=0.15$ and $0.2 \mathrm{~m}$, respectively. For a given flow rate, dissipation in the central region does not have any effect of rotational speed. At $r>0.02 \mathrm{~m}$, effect of rotational speed is prominent. Figure 7(c) shows the effect of flow rate on dissipation rate in central region. The central zone $\left(\sim 10^{5} \mathrm{~W} / \mathrm{kg}\right)$ has almost order of magnitude higher turbulent dissipation rate compared to periphery. The increase of flow rate from $110 \mathrm{~mL} / \mathrm{min}$ to $300 \mathrm{~mL} / \mathrm{min}$ increased the dissipation rate from 13,000 to $37,000 \mathrm{~W} / \mathrm{kg}$. This value is comparable to those obtained in high shear mixers and emulsifiers used in chemical and allied industries to get microemulsions. Typical correlation for droplet diameter in 


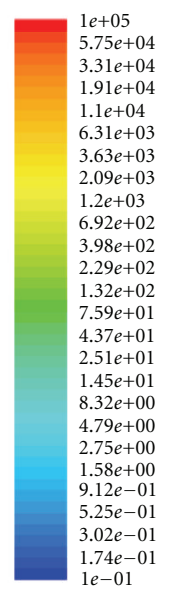

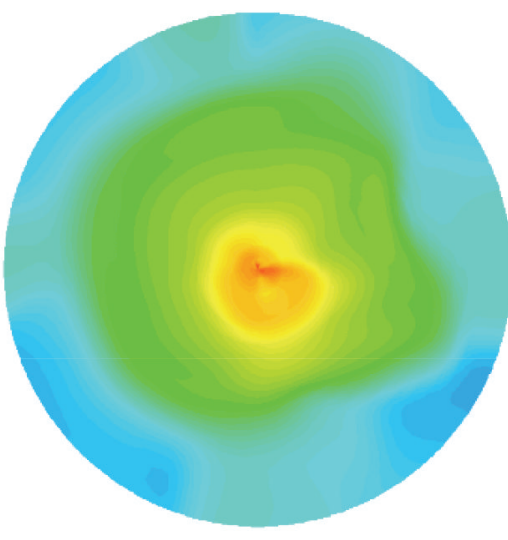

(a)

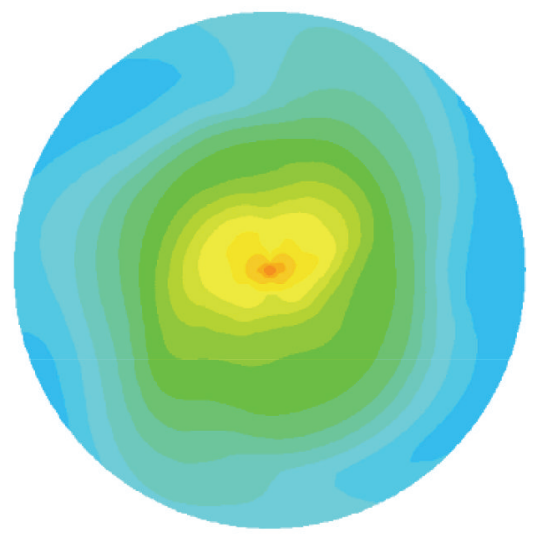

(b)

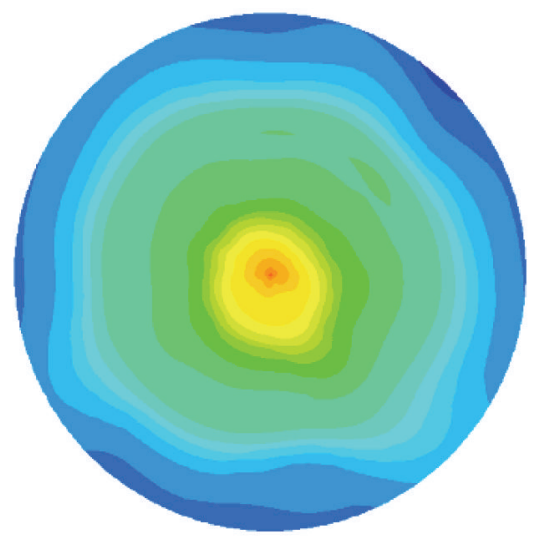

(c)

Figure 6: contour plot of turbulent dissipation rate $(\varepsilon)$ inner region $(r=0$ to $r=0.01 \mathrm{~m})[z=0.00075 \mathrm{~m}][D=0.2 \mathrm{~m}]$. Upper disk rotation speed $=1000 \mathrm{rpm}$, (a) $300 \mathrm{~mL} / \mathrm{min}$, (b) $190 \mathrm{~mL} / \mathrm{min}$, (c) $110 \mathrm{~mL} / \mathrm{min}$.

high shear is provided by Davies [25]. Many of the qualitative observations made by Dehkordi [1] can be explained in quantitative manner by present CFD simulations. Some of their observations are reported below

\begin{abstract}
"An increase in extraction efficiency may be noticed by increasing the upper disk speed. Such a behavior is the consequence of increasing the mixing and turbulence, which control the present extraction process."
\end{abstract}

"In addition, an increase in the upper disk speed, $N$, increases the overall volumetric mass transfer coefficient, $k_{L} \underline{a}$. This behavior may be explained by increasing the shear forces exerted on the phases and the turbulence that leads to an increase in the surface renewal mechanism and, hence, an increase in the interfacial mass-transfer area, $\underline{a} . "$

The volume average dissipation rate as a function of rotation speed shows $550 \%$ increase in dissipation rate from 600 to $1400 \mathrm{rpm}$. In case of very high shear flows, the transfer coefficients are observed to be proportional to square root of local turbulent dissipation rate. The interfacial area (i.e., drop size) is governed by the flow rate compared to rotation speed as maximum shearing takes place in the central region and drop breakup as well. The upper disc rotation stabilizes the drops to certain extent and overall dissipation may not have a control on the interfacial area. Hence, overall $k_{L} a$ varies as 0.5 power of turbulent dissipation rate. Hence the expected improvement in extraction efficiency is $(377 / 58)^{0.5}$ $=2.55$. The ratio of experimental $k_{L} a$ at 1400 and $600 \mathrm{rpm}$ is $(13.5 / 8)=1.7$.

Dehkordi [1] fitted a correlation based on experimental data for overall mass transfer coefficient is given by (5). $V_{d}$ is microextractor volume in liter, $Q_{A}$ is the flow rate in liter/min, $D$ is disc diameter in $\mathrm{m}$, and $N$ is rotational speed in $\mathrm{rpm}$

$$
k_{L} \underline{a}\left(\mathrm{~s}^{-1}\right)=0.003 D^{-0.1} V_{d}^{-0.6} Q_{A}^{0.59} N^{0.41} .
$$

It can be seen from this correlation that aqueous and organic phase flow rate has significant effect on the overall mass transfer coefficient (as it governs droplet breakup rate and hence interfacial area) and followed by rotation speed (affects true mass transfer coefficient in the domain and 


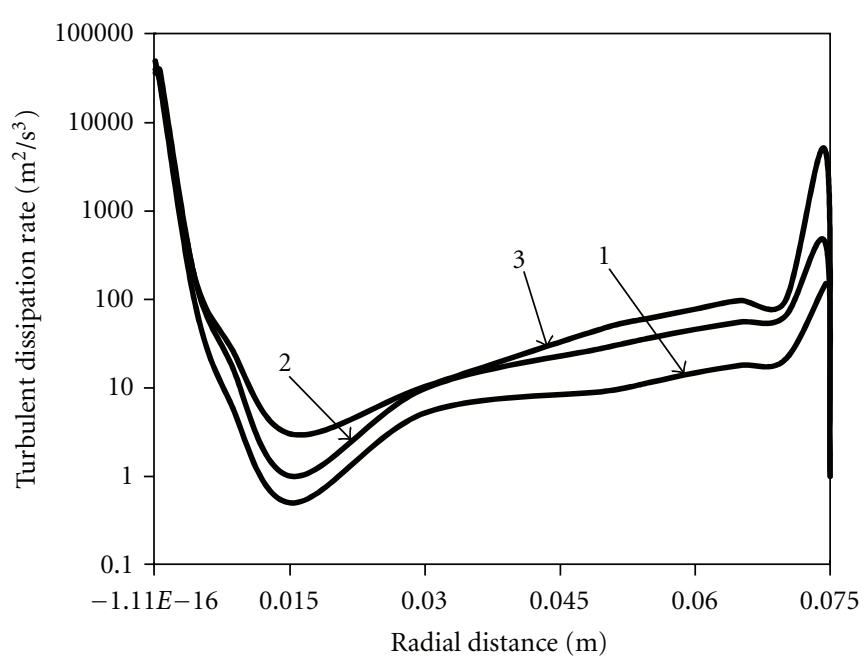

(a)

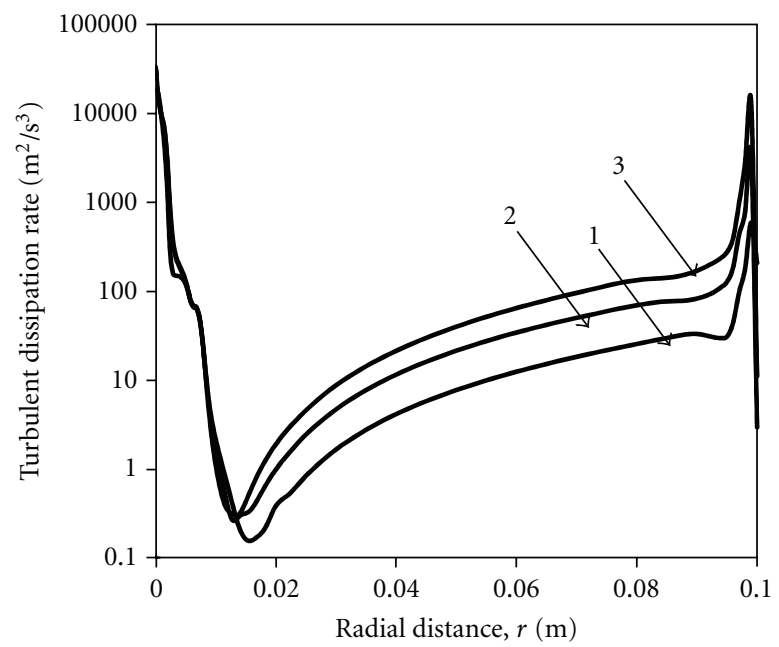

(b)

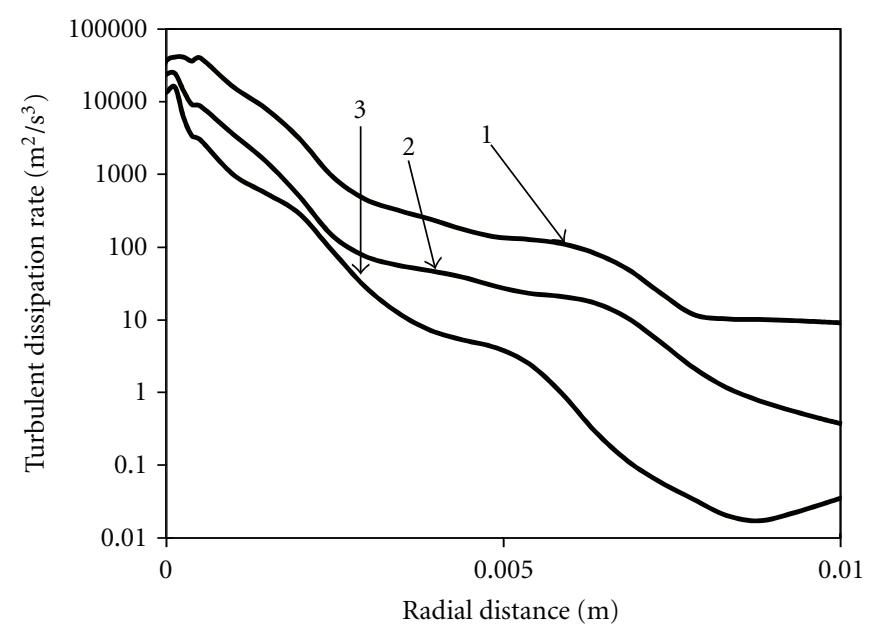

(c)

Figure 7: Variation of turbulent dissipation rate $(\varepsilon)$ along radial coordinate $[z=0.00075 \mathrm{~m}]$. (a) Disc diameter: $0.15 \mathrm{~m}$, flow rate: $300 \mathrm{~mL} / \mathrm{min}$, line 1: $600 \mathrm{rpm}$, line 2: $1000 \mathrm{rpm}$, line 3: $1400 \mathrm{rpm}$. (b) Disc diameter: $0.20 \mathrm{~m}$, flow rate: $300 \mathrm{~mL} / \mathrm{min}$, line 1: $600 \mathrm{rpm}$, line 2: $1000 \mathrm{rpm}$, line 3: $1400 \mathrm{rpm}$. (c) Disc diameter: $0.15 \mathrm{~m}$, rotation speed: $1000 \mathrm{rpm}$, line 1: $300 \mathrm{~mL} / \mathrm{min}$, line 2: $190 \mathrm{~mL} / \mathrm{min}$, line 3: $110 \mathrm{~mL} / \mathrm{min}$.

stabilizing the drops). Experimental observations in various conventional contactors such as bubble columns, stirred vessels, jet mixers, high shear mixers, annular centrifugal extractors, and so forth suggest that the overall mass transfer coefficient is a function of power input per unit volume under turbulent conditions. However, in case of TOJCD, the power input per unit volume affects the true mass transfer coefficient $\left(k_{L}\right)$, and the interfacial area is governed by the impinging jets which have energy proportional to nozzle velocity. Equation (6) is modified correlation to incorporate this theory of turbulence for microextractor. Table 2 shows the power consumed $(P)$ per unit mass $(M)$ for different cases along with the experimental mass transfer coefficient obtained by Dehkordi $[1,2]$. We have

$$
k_{L} \underline{a}\left(\mathrm{~s}^{-1}\right)=A\left(\frac{P}{M}\right)^{B} V_{N}^{C}
$$

MATLAB software is used to estimate the best fit values of $A, B$, and $C$ based on the data provided in Table 2 . The best fit values obtained are $A=0.018, B=0.22$, and $C=0.78$. The revised correlation is provided as (7). These values clearly indicate that the nozzle velocity plays much more important role compared to the rotation speed of upper disc. We have

$$
k_{L} \underline{a}\left(\mathrm{~s}^{-1}\right)=0.018\left(\frac{P}{M}\right)^{0.22} V_{N}^{0.78} .
$$

The parity plot of experimental and predicted (from (7)) mass transfer coefficient is shown in Figure 8. It can be seen that the predictions are in very good agreement with the experimental mass transfer coefficient. Figure 9 shows the variation of mass transfer coefficient with rotation speed and jet velocity. Jet velocity has significant impact on mass transfer than rotation speed. The CFD simulation has provided valuable information about the power dissipation 
TABLE 2: Power consumption per unit mass from CFD and experimental $k_{L} \underline{a}[1,2]$.

\begin{tabular}{lcccccc}
\hline Sr. no. & RPM & Aq flow rate $Q_{A}(\mathrm{~mL}$ per $\mathrm{min})$ & $D(\mathrm{~m})$ & $V_{N}(\mathrm{~m} / \mathrm{s})$ & $P / M \mathrm{~W} / \mathrm{kg}($ present CFD $)$ & $k_{L} \underline{a}\left(\mathrm{~s}^{-1}\right) \times 10^{4}(\mathrm{Dehkordi}[1,2])$ \\
\hline 1 & 600 & 300 & 0.20 & 6.36 & 58 & 1837 \\
2 & 1000 & 300 & 0.20 & 6.36 & 149 & 2275 \\
3 & 1400 & 300 & 0.20 & 6.36 & 376 & 2819 \\
4 & 600 & 190 & 0.20 & 4.03 & 50 & 1354 \\
5 & 1000 & 190 & 0.20 & 4.03 & 180 & 1520 \\
6 & 1400 & 190 & 0.20 & 4.03 & 370 & 2005 \\
7 & 600 & 110 & 0.20 & 2.33 & 50 & 837 \\
8 & 1000 & 110 & 0.20 & 2.33 & 177 & 1033 \\
9 & 1400 & 110 & 0.20 & 2.33 & 397 & 1328 \\
\hline
\end{tabular}

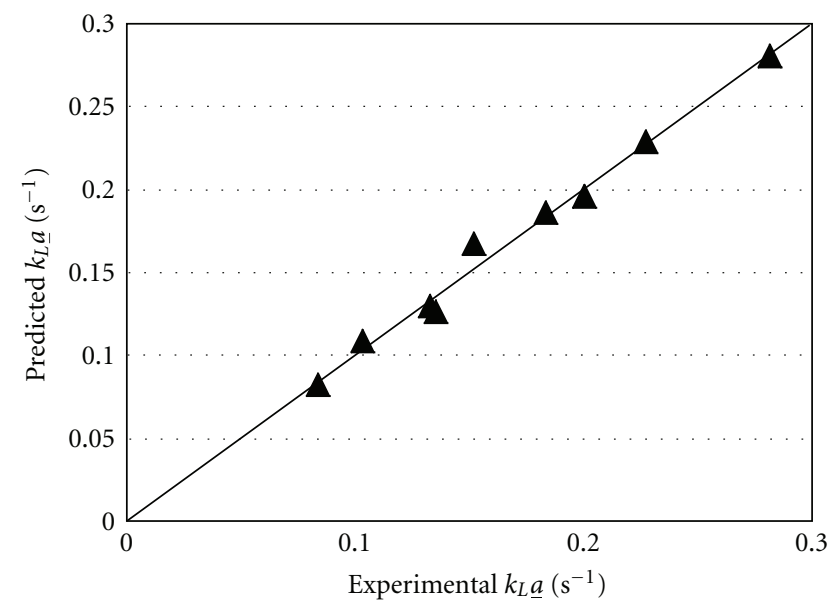

FIGURE 8: Parity plot of overall mass transfer coefficient prediction from proposed correlation with experimental data of Dehkordi [1, 2].

per unit mass, which can be used to obtain semiempirical models with deeper insight into transport phenomena.

\section{Conclusion}

Microreactor technology is becoming popular in chemical process industries due to ease of scale-up and better energy efficiency. The microextractor design considered in the present work gives almost one theoretical stage with excellent extraction efficiency. The major turbulence generation (subsequent breakup of drops and mass transfer) is dominated by the rotation of top disc in peripheral region and jet velocity in the central region. The inertial force of the jet and the centrifugal force are going to be few orders of magnitude higher than the viscous forces. In this work, twoopposed-jet microextractor has been studied using Reynolds stress model. The Reynolds stress model is very effective in solving stagnation flows with very strong anisotropy. The average turbulent dissipation rate for 600, 1000, and $1400 \mathrm{rpm}$ was 58,150 , and $377 \mathrm{~W} / \mathrm{kg}$, respectively. The CFD simulation with small eddy model is capable of predicting transport phenomena in this microextractor. The transport

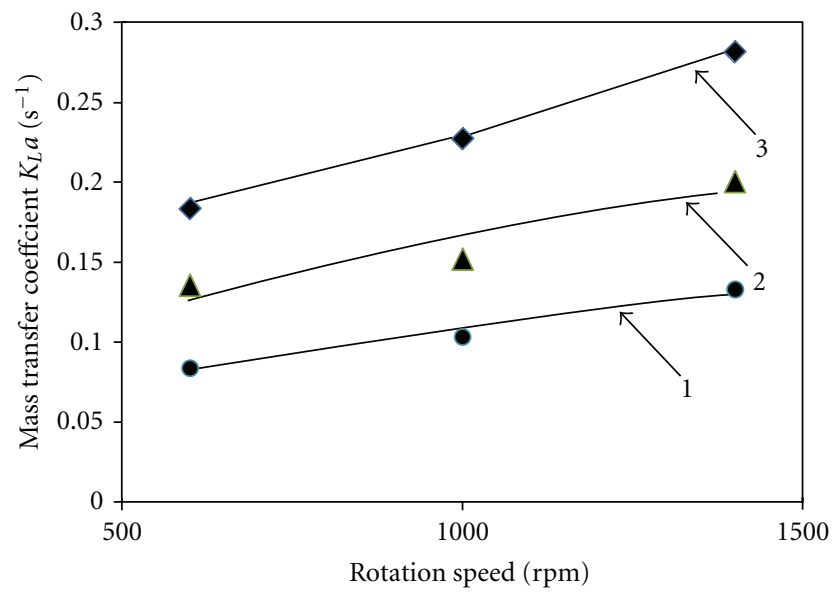

Figure 9: Variation of mass transfer coefficient with disk rotation speed; Prediction (correlation using CFD data); Line 1: $110 \mathrm{~mL} / \mathrm{min}$; Line 2: $190 \mathrm{~mL} / \mathrm{min}$; Line 3: $300 \mathrm{~mL} / \mathrm{min}$, EXPT $110 \mathrm{~mL} / \mathrm{min}, \boldsymbol{\Delta}$ EXPT $190 \mathrm{~mL} / \mathrm{min}$, EXPT $300 \mathrm{~mL} / \mathrm{min}$.

phenomena are governed by small-scale eddies, and drop size is controlled by the shear in extractor volume. The understanding gained from the single phase CFD simulation can give very useful insights into two-phase extraction processes. CFD simulations clearly bring out the fact that the extractor efficiency is strongly dependent on the jet velocity and rotation speed of the upper disc. However, the effect of change of the disc diameter is not significant.

\section{Notations}
a: $\quad$ Interfacial area $\left(\mathrm{m}^{2} / \mathrm{m}^{3}\right)$
$d_{N}$ : Nozzle diameter $(\mathrm{m})$
$D: \quad$ Disc diameter $(\mathrm{m})$
$D_{t}$ : Turbulent diffusion coefficient $\left(\mathrm{m}^{2} / \mathrm{s}\right)$
$k$ : Turbulent kinetic energy $\left(\mathrm{m}^{2} / \mathrm{s}^{2}\right)$
$k_{L}$ : True mass transfer coefficient $(\mathrm{m} / \mathrm{s})$
$M$ : $\quad$ Mass of fluid in extractor, $\mathrm{kg}$
$N$ : $\quad$ Rotation speed of upper disc, rpm
$p_{i}: \quad$ Pressure $\left(\mathrm{N} / \mathrm{m}^{2}\right)$
$\left\langle p_{i}\right\rangle$ : Time-averaged pressure $\left(\mathrm{N} / \mathrm{m}^{2}\right)$
$P: \quad$ Power dissipated (W) 
$Q_{A}:$ Volumetric flow rate $\left(\mathrm{m}^{3} / \mathrm{s}\right)$

$S_{k i}:$ Shear rate $\left(\mathrm{s}^{-1}\right)=$ $1 / 2\left(\partial\left\langle u_{k}\right\rangle / \partial x_{i}+\partial\left\langle u_{i}\right\rangle / \partial x_{k}\right)$

$\left\langle u_{i}\right\rangle:$ Time average of velocity $(\mathrm{m} / \mathrm{s})$

$V_{d}$ : Extractor volume, $\mathrm{m}^{3}$

$V_{N}$ : Nozzle velocity, $\mathrm{m} / \mathrm{s}$

$x_{i}$ : Coordinate distances in $i$ direction where $i=1,2,3(\mathrm{~m})$.

\section{Greek Letters}

$\delta_{i j}$ : Kronekar delta $=1$ if $i=j ;=0$ if $i \neq j$

$\delta: \quad$ Gap width $(\mathrm{m})$

$\varepsilon: \quad$ Energy dissipation rate $\left(\mathrm{m}^{2} / \mathrm{s}^{3}\right)$

$\mu$ : Dynamic viscosity $(\mathrm{kg} / \mathrm{ms})$

$\mu_{t}$ : Turbulent viscosity $(\mathrm{kg} / \mathrm{ms})$

$v$ : Kinematic viscosity $\left(\mathrm{m}^{2} / \mathrm{s}\right)$

$v_{t}:$ Eddy viscosity $\left(\mathrm{m}^{2} / \mathrm{s}\right)$

$\Pi_{i j}$ : Pressure strain tensor, $\left(\mathrm{N} / \mathrm{m}^{2} \mathrm{~s}\right)$

$\rho:$ Density of liquid $\left(\mathrm{kg} / \mathrm{m}^{3}\right)$

$\sigma_{\varepsilon}:$ Parameter in $\varepsilon$ equation in RSM

$\tau_{i j}$ : Reynolds Stress $\left(\mathrm{m}^{2} / \mathrm{s}^{2}\right)=-\left\langle u_{i}^{\prime} u_{j}^{\prime}\right\rangle$.

\section{Abbreviations}

CFD: Computational fluid dynamics

RSM: Reynolds stress modelling

TOJCD: Twin-opposed-jet contacting device.

\section{References}

[1] A. M. Dehkordi, "Application of a novel-opposed-jets contacting device in liquid-liquid extraction," Chemical Engineering and Processing, vol. 41, no. 3, pp. 251-258, 2002.

[2] A. M. Dehkordi, "Liquid-liquid extraction with chemical reaction in a novel impinging-jets reactor," AIChE Journal, vol. 48, no. 10, pp. 2230-2239, 2002.

[3] B. D. Kadam, J. B. Joshi, S. B. Koganti, and R. N. Patil, "Hydrodynamic and mass transfer characteristics of annular centrifugal extractors," Chemical Engineering Research and Design, vol. 86, no. 3, pp. 233-244, 2008.

[4] J. Saien, S. A. E. Zonouzian, and A. M. Dehkordi, "Investigation of a two impinging-jets contacting device for liquid-liquid extraction processes," Chemical Engineering Science, vol. 61, no. 12, pp. 3942-3950, 2006.

[5] R. L. Yadav and A. W. Patwardhan, "Design aspects of pulsed sieve plate columns," Chemical Engineering Journal, vol. 138, no. 1-3, pp. 389-415, 2008.

[6] C. S. Mathpatii, M. V. Tabib, S. S. Deshpande, and J. B. Joshi, "Dynamics of flow structures and transport phenomena, 2. Relationship with design objectives and design optimization," Industrial and Engineering Chemistry Research, vol. 48, no. 17, pp. 8285-8311, 2009.

[7] A. Tamir, Impinging Streams Reactors: Fundamentals and Applications, Elsevier, Amsterdam, The Netherlands, 1994.

[8] B. N. Murthy and J. B. Joshi, "Assessment of standard $k-\varepsilon$, RSM and LES turbulence models in a baffled stirred vessel agitated by various impeller designs," Chemical Engineering Science, vol. 63, no. 22, pp. 5468-5495, 2008.
[9] C. S. Mathpati, S. S. Deshpande, and J. B. Joshi, "Computational and experimental fluid dynamics of jet loop reactor," AIChE Journal, vol. 55, no. 10, pp. 2526-2544, 2009.

[10] S. S. Deshmukh, S. Vedantam, J. B. Joshi, and S. B. Koganti, "Computational flow modeling and visualization in the annular region of annular centrifugal extractor," Industrial and Engineering Chemistry Research, vol. 46, no. 25, pp. 8343-8354, 2007.

[11] S. J. Wang and A. S. Mujumdar, "Mixing characteristics of 3D confined turbulent opposing jets," in International Workshop and Symposium on Industrial Drying, pp. 309-316, Mumbai, India, December 2004.

[12] S. J. Wang, S. Devahastin, and A. S. Mujumdar, "Effect of temperature difference on flow and mixing characteristics of laminar confined opposing jets," Applied Thermal Engineering, vol. 26, no. 5-6, pp. 519-529, 2006.

[13] S. J. Wang and A. S. Mujumdar, "Flow and mixing characteristics of multiple and multi-set opposing jets," Chemical Engineering and Processing, vol. 46, no. 8, pp. 703-712, 2007.

[14] A. Abdel-Fattah, "Numerical and experimental study of turbulent impinging twin-jet flow," Experimental Thermal and Fluid Science, vol. 31, no. 8, pp. 1061-1072, 2007.

[15] E. Gavi, D. L. Marchisio, and A. A. Barresi, "CFD modelling and scale-up of Confined Impinging Jet Reactors," Chemical Engineering Science, vol. 62, no. 8, pp. 2228-2241, 2007.

[16] A. W. Kleingeld, L. Lorenzen, and F. G. Botes, “The development and modelling of high-intensity impinging stream jet reactors for effective mass transfer in heterogeneous systems," Chemical Engineering Science, vol. 54, no. 21, pp. 4991-4995, 1999.

[17] D. L. Marchisio, "Large Eddy Simulation of mixing and reaction in a Confined Impinging Jets Reactor," Computers and Chemical Engineering, vol. 33, no. 2, pp. 408-420, 2009.

[18] C. Niamnuy and S. Devahastin, "Effects of geometry and operating conditions on the mixing behavior of an in-line impinging stream mixer," Chemical Engineering Science, vol. 60, no. 6, pp. 1701-1708, 2005.

[19] W. Li, Z. Sun, H. Liu, F. Wang, and Z. Yu, "Experimental and numerical study on stagnation point offset of turbulent opposed jets," Chemical Engineering Journal, vol. 138, no. 1-3, pp. 283-294, 2008.

[20] D. R. Unger and F. J. Muzzio, "Laser-induced fluorescence technique for the quantification of mixing in impinging jets," AIChE Journal, vol. 45, no. 12, pp. 2477-2486, 1999.

[21] Z. G. Sun, W. F. Li, and H. F. Liu, "Study on the radial jet velocity distribution of two closely spaced opposed jets," International Journal of Heat and Fluid Flow, vol. 30, no. 6, pp. 1106-1113, 2009.

[22] W. C. Reynolds, "Fundamentals of Turbulence for Turbulence Modeling and Simulation," Report No. 755, Lecture Notes for Von Karman Institute, Agard., 1987.

[23] B. E. Launder, "Second-moment closure and its use in modelling turbulent industrial flows," International Journal for Numerical Methods in Fluids, vol. 9, no. 8, pp. 963-985, 1989.

[24] K. Hanjalić, "Advanced turbulence closure models: a view of current status and future prospects," International Journal of Heat and Fluid Flow, vol. 15, no. 3, pp. 178-203, 1994.

[25] J. T. Davies, "Drop sizes of emulsions related to turbulent energy dissipation rates," Chemical Engineering Science, vol. 40, no. 5, pp. 839-842, 1985. 

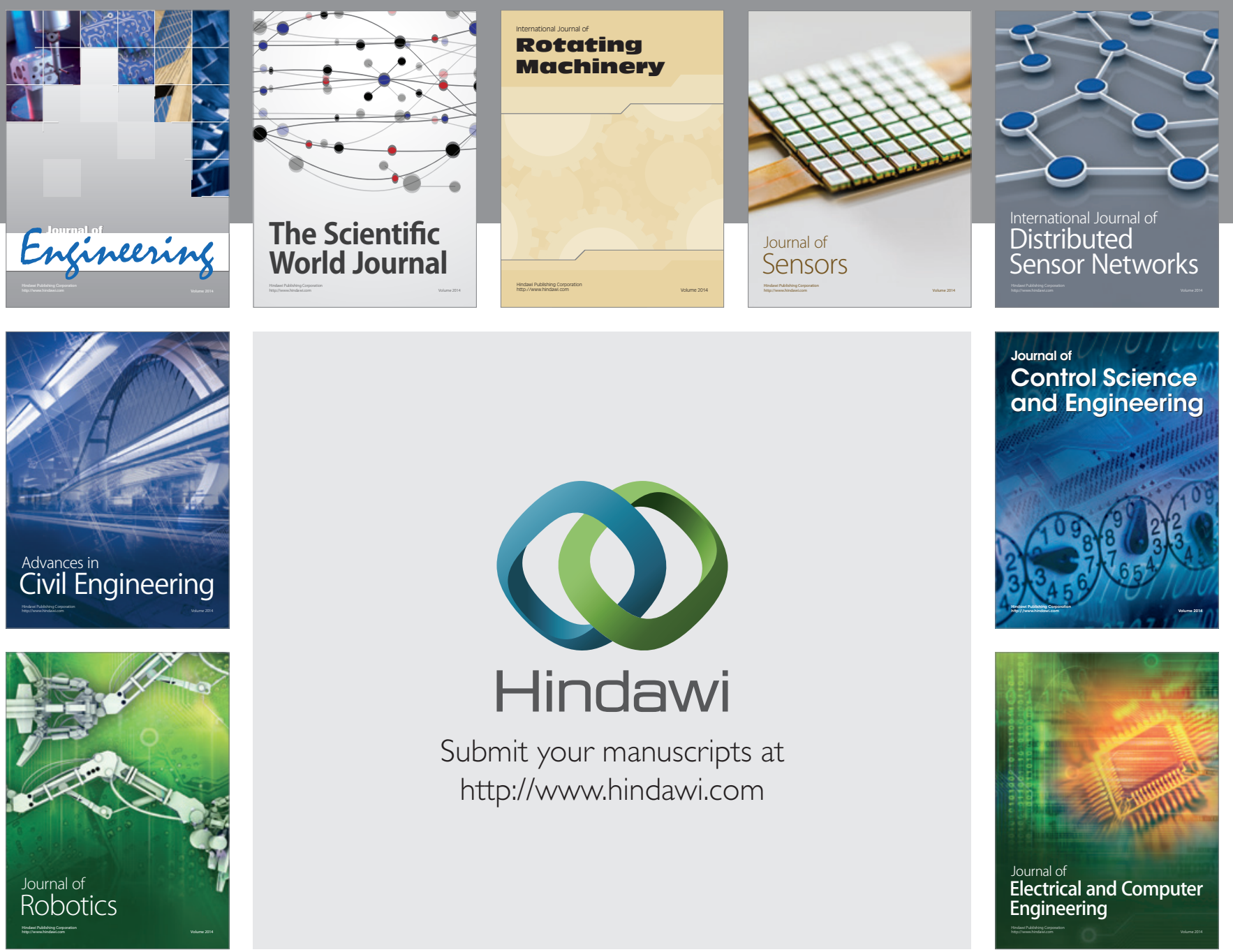

Submit your manuscripts at

http://www.hindawi.com
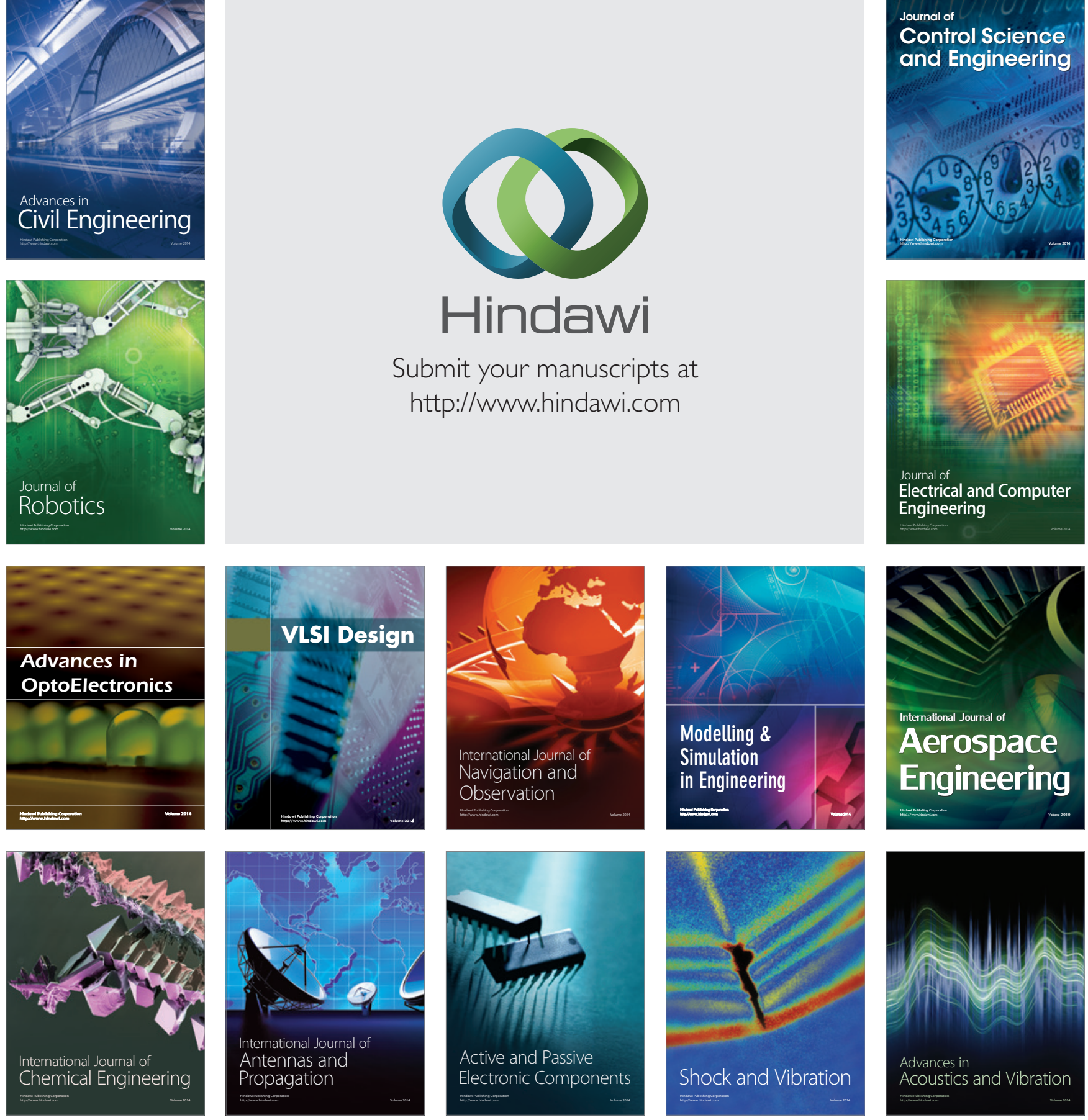